Rochester Institute of Technology

RIT Scholar Works

Presentations and other scholarship

Faculty \& Staff Scholarship

$10-1-2017$

\title{
Use of Role-play and Gamification in a Software Project Course
}

Bruce R. Maxim

University of Michigan-Dearborn

Stein Brunvand

University of Michigan-Dearborn

Adrienne Decker

Rochester Institute of Technology

Follow this and additional works at: https://scholarworks.rit.edu/other

\section{Recommended Citation}

B. R. Maxim, S. Brunvand and A. Decker, "Use of role-play and gamification in a software project course," 2017 IEEE Frontiers in Education Conference (FIE), Indianapolis, IN, 2017, pp. 1-5, doi: 10.1109/ FIE.2017.8190501.

This Conference Proceeding is brought to you for free and open access by the Faculty \& Staff Scholarship at RIT Scholar Works. It has been accepted for inclusion in Presentations and other scholarship by an authorized administrator of RIT Scholar Works. For more information, please contact ritscholarworks@rit.edu. 


\section{Use of Role-play and Gamification in a Software Project Course}

\author{
Bruce R. Maxim, Stein Brunvand \\ Computer and Information Science \\ University of Michigan-Dearborn \\ Dearborn, MI - USA \\ \{bmaxim, sbrunvan\}@umich.edu
}

\author{
Adrienne Decker \\ School of Interactive Games and Media \\ Rochester Institute of Technology \\ Rochester, NY - USA \\ Adrienne.Decker@ rit.edu
}

\begin{abstract}
Soft skills are increasingly important to the engineering profession and course modifications are often needed to ensure students have opportunities to practice them prior to graduation. This suggests that engineering programs need to go beyond simply offering industry-based capstone courses and internships. Role-play has a long history as a tool for learning. It can be used to simulate real world practices in environments where consequences can be mitigated safely. In this paper, we discuss the use of team role-play activities to simulate the experience of working in a professional, game development studio as a means of enhancing an advanced undergraduate game design course. In conjunction with the role-play, a gamification framework was used within the course to allow students to customize their course participation. Gamification was used to reward students for compliance with software process steps and for taking the initiative to improve their "soft skills". In this project, allowing students to negotiate the nature of their activities and rewards helped them develop those skills. We are using student feedback and our own lessons learned to plan the next iteration of this course.
\end{abstract}

\section{Keywords—soft skills; role-play; gamification; game design}

\section{INTRODUCTION}

Many courses offered by the College of Engineering and Computer Science (CECS) at the University of MichiganDearborn rely heavily on lectures as the primary vehicle of instruction. This is even true of courses that emphasize student project work. The authors have noticed gaps in students' software engineering skills when they begin their capstone projects. It is the authors' belief that part of the reason for these gaps is that students were not asked to apply these skills in project settings in their previous courses. Often, instructors rely on just-in-time learning to fill in the knowledge gaps students may have when they begin their project work.

\section{A. Active Learning}

Many engineering educators regard experiential or active learning as the best way to train the next generation of software engineers. Soft skills are increasingly important to the engineering profession and course modifications are often needed to ensure students have opportunities to practice them prior to graduation. The authors believe that introducing active learning opportunities prior to the senior year can improve the students' software engineering and game design skills.

Active learning is "embodied in a learning environment where the teachers and students are actively engaged with the content through discussions, problem-solving, critical thinking, debate and a host of other activities that promote interaction among learners, instructors and the material"[1]. Prince defines active learning as a classroom activity that requires students to do something other than listen and take notes [2]. Active learning tools complement or replace lectures and make class delivery more interesting to the learners.

Specifically, active learning helps students develop problem-solving, critical-reasoning, and analytical skills, all of which are valuable tools that prepare students to make better decisions, become better students and, ultimately, better employees [2]. Raju and Sankar [3] undertook a study to develop teaching methodologies that could bring real-world issues into engineering classrooms. The results of their research led to recommendations for funding agencies and educators on the importance of developing interdisciplinary technical case studies that allow engineering innovations to be communicated to students in the classroom.

\section{B. Role-Play}

Role-play has a long history as a tool for learning. Roleplay can be used to simulate real world practices in environments where consequences can be mitigated safely [4]. It makes sense that some investigators have examined the use of role-play in software engineering education.

Role-play has been used as a way to engage the student as part of the requirements engineering process to help them understand how a user would perceive the system behavior in a human computer interaction (HCI) course [5, 6]. Zowghi and Paryani had students play the roles of both customer and developer in the requirements engineering process to help them appreciate the process from multiple perspectives [7]. Börstler used role-play and CRC (class-responsibilitycollaborator) cards to introduce students to object-oriented programming concepts [8].

Information Technology students interacted more deeply with course material when they assumed the roles of designers and developers while working through several realistic

This project was partially supported by the University of MichiganDearborn Creative Teaching Fund 
problem scenarios [9]. For example, Second Life has been used as a platform to support virtual interactions for role-play in which Enterprise Resource Planning students were playing employees of a fictional company [10].

The use of real-world, community-based projects has been recognized as a good way to expose students to meaningful software development $[11,12]$. Students often become more invested in their project when they see that their products are more than simply a paper design. An important aspect of software engineering education is the development of soft skills such as communication and project management. These skills are hard to practice without a long-term project to manage. Some very good on-line simulations have been created in which the computer allows the users to manage simulated projects. These simulations are often structured as role-plays in which users are project managers who are able to see the consequences of their decisions $[13,14,15]$.

In this paper, the authors discuss the use of team role-play activities to simulate the experience of working in a professional, game development studio as a means of enhancing an advanced undergraduate game design course (CIS 488 Game Design and Implementation 2). The term-long project in this course requires incremental product deliveries using accepted game industry milestones.

In the version of the course described in this paper, a back story is created in which the students are placed in the position of developers/owners of a failing game company. The students' goal is to create new and original products to ensure the survival of the company. This back story is used to provide a meaningful context for the term project activities. This backstory is discussed in greater detail in Decker and Simkins [16]. Decker and Simkins used this approach in a game development processes class where the outcomes for the students were not assessed based strictly on what they produced but rather the processes by which they created those artifacts. That is, student teams were discouraged from simply "finishing the product" in a crunch mentality. The process and engagement with it was the goal.

The instructional role-play activities adapted from Decker and Simkins' emphasize industry best practices for both technical and soft skills (project management, communication, marketing, and interdisciplinary design). Students often have diverse interests in studying game development (level design, animation, audio development, testing). The gamification framework created for the CIS 488 course allows them to focus on one or more of their interests. Our role-play scenario allows for a natural introduction of business and legal concerns that might arise during the technical development of their game products.

\section{Gamification}

In conjunction with the role-play, a gamification framework was created and used within the course to allow students to customize their course participation. Gamified learning or the gamification of learning has been defined as the use of game design elements in non-game settings in order to increase motivation and attention on a task [18, 19]. James Gee has identified thirty-six learning principles that are present in good games [20]. These learning principles provide the backbone for good game design and, in turn, can be used as guiding principles when designing a gamified learning environment. For instance, good games provide players with information when they need it and within the context in which the information will be used [21]. Effective game design includes challenging players so they are routinely working at the edge of their abilities and knowledge, also known as their zone of proximal development [22]. Having students, or players, operate within this optimal learning zone helps keep them engaged and encourages them to learn more in order to meet the demands of the next challenge.

Games can promote collaboration, requiring players to share knowledge and skills in order to be successful [21]. Games that promote and reward teamwork have a positive impact on the development of prosocial skills [23]. Gee also contends that well designed games are motivational specifically because of the different learning principles outlined previously [21]. Working at the limits of their abilities keeps players engaged as they continue to take on new challenges [24]. Gee refers to this process as a cycle of expertise, which requires players to constantly learn, act, revise and learn again in order to demonstrate mastery and be successful in a game [20]. In addition to the motivational aspect of the cognitive element of games, Lee and Hammer suggest that the social and emotional aspects of rewards and consequences earned in gaming environments contribute to motivation as well [25]. The key is finding a balance between the positive and negative outcomes so that players remain motivated to proceed and don't become overwhelmed or discouraged [18]. A well-designed game can also motivate players to stay engaged by enhancing the value of the task or tasks being completed [26]. This is particularly beneficial with educational games focused on school related subjects that students might not otherwise choose to immerse themselves within. Toth and Kayler created a role-play game (RPG) in which used quests as a means of motivating students to complete the assignments in networking and operating systems courses [27].

Gamification can be used as a means of promoting rewards for completing tasks. In this case, we can reward students (the employees of the role-play) for compliance to software process steps and for taking the initiative to improve their "soft skills". In this way, we are trying to resolve some of the discrepancies in personal efforts that are often present in student project work. Allowing students to negotiate the nature of their activities and rewards up front often goes a long way to ensuring that all students are engaged for the entire semester. It is our expectation that, by providing more diverse learning opportunities, our students will be better equipped for the engineering profession upon graduation. We are using student feedback and our own lessons learned to plan the next iteration of this course.

\section{COURSE StURCTURE}

\section{A. Course Activities}

CIS 488 meets one day a week for 3 hours over a 14 week semester. During the first class period students were introduced 
to the back story of the role-play and how it would affect the conduct of the course. In previous offerings of this course much of the class time was spent observing instructor lectures on Unreal4 programming techniques. In the current course offering most of the class time was spent in game design studio role-play activities. Often classes began with an all hands meeting to introduce the day's role-playing activities. Students were expected to use video tutorials outside of class to learn to use the Unreal4 Blue Print system and level editor.

The fictitious company created for the role-play had a tradition of using a green light system for continuing or stopping development of game products. The first task was for each company developer to do a quick market research review and create a pitch for an innovative game product. The top five pitches were selected by class vote and the pitch authors were allowed to recruit 4 or 5 team members at the third class period.

Each team was asked to provide a representative for a committee to write a company-wide software process standards document based on the scrum framework. A contest was held within the company to create a new name and logo. The developers selected their favorite and SafeSpot Games was launched.

Each team's first task was to create a game design document and a business plan for their game. To assist them in this task two local game company owners acting in the role of business consultants discussed their experiences with creating a company and bringing their first games to market. While this document was being developed teams were asked to begin creating both a one page marketing piece and a 30 second elevator pitch for their games. These were reviewed and critiqued by the company developers several times throughout the semester.

Peer review was used to provide feedback on the first draft of each milestone artifact (both documents and running game prototypes). Developers were required to review 3 artifacts and were allowed to review more if they wished. The team leaders judges the quality of each review of their team's game as meaningful or valueless. Students were awarded 2 points for good reviews and 1 point for valueless reviews. The number of valueless reviews dropped greatly after the first round of peer reviews and the number of extra reviews from students increased as well.

The second team deliverable was a game alpha prototype which included one complete logic path, a draft user document, and a working installer. This delivery signaled the end of the first sprint in the scrum framework. These games were evaluated for quality of game play. The company as a whole looked at the productivity of each team. The team leads were asked to make an oral presentation to confirm that they have sufficient resources to complete their game products on time (the end of the semester was designated as the end of the fiscal year). All developers discussed the future of the game products and decided (without the instructors influence) to cancel one of the projects. The developers from the canceled project were reassigned to existing development teams. This turned out to be a good decision as the productivity of each team went up for the remainder of the course.
The third team deliverable was a beta prototype which needed to accommodate a requirement change. The change resulted in the addition a significant game AI (artificial intelligence) element to their evolving game design. This deliverable also included the creation of the final game design document and test plan. These artifacts were reviewed and tested by developers from other teams. Each of the beta prototype games was given the green light to continue.

The final team deliverable was the gold release prototype and a marketing presentation that included a video piece to promote their game product. The video presentations were previewed inside the company. The gold prototypes were showcased at a launch party where students from all parts of the campus were given a chance to play the games. Company developers scored each game (other than their own) using a rubric provided by the instructor. The average of this score was used as the grade of the prototype.

The students were involved in several role-play scenarios through the semester, in addition to greenlighting the games. One scenario involved coming up with a creative solution to finding resources to resolve maintenance issue left unfulfilled on a contract inherited by the previous owners while minimizing impact on the games under development. A second involved crafting a response to concerns about a competing company running advertisements for games very similar to two soon to be released SafeSpot games. A third focused on planning for sequels to each game under development.

One element of this class that was harder to fit into the roleplay was the assignment where each developer uses their own game to illustrate game design features from Schell's book of game design lenses [28]. In this assignment, each student selects a group of three related lenses and creates a 20 minute presentation discussing how these lenses illustrate qualities from their game or not. This is sold as continuing education or perfective maintenance to the company developers.

\section{B. Gamification}

One problem the authors have observed on many student projects was the fact that some students provide little effort to the final product or they feel their contributions to the final product were not rewarded by their grade. Students worked in teams to create the milestone documents and prototypes created in this course. In the past, the course instructor asked each student to grade the participation of each team member (including themselves) using a score of 0 to 5. Students were also expected to create a bulleted list of the tasks completed by each team member. The average of these scores was added to the team score. The instructor penalized people who failed to make significant contributions. Often the loss of 2 or 3 points on an assignment was not enough to encourage students to be active team contributors.

In the latest version of the course, a gamification framework was created, where the points for the team artifacts became part of the core or required work for everyone and the individual work products become part of the elective work. The individual work includes the peer evaluations, the lens presentations, attendance, programming, level design, testing, project management, and art asset creation. In keeping with 
the spirit of the role-play students determined which game production activities were important for successful project completion and their relative point values $(5,3$, or 2$)$. These are shown in Table I.

TABLE I. DEVELOPMENT TASK VALUES

\begin{tabular}{|c|l|}
\hline $\begin{array}{c}\text { Point } \\
\text { Values }\end{array}$ & \multicolumn{1}{c|}{ Game Development Activities } \\
\hline 5 & $\begin{array}{l}\text { Programmer, AI Programmer, UX Programmer, } \\
\text { 3D Prop Builder, Character Animator }\end{array}$ \\
\hline 3 & $\begin{array}{l}\text { Level Designer, 2D Texture Artist, Project } \\
\text { Management, Document Manager, Repository } \\
\text { Manager }\end{array}$ \\
\hline 2 & Audio Designer, Test Engineer, Cinematic Artist \\
\hline
\end{tabular}

For the most part computer science and software engineering students take this class, so it is not too surprising that programming was given the highest importance by these students. These points were mapped to a time card where the maximum points the students earned for their prototype work matched the maximum number of points awarded the team documents submitted for that turn in. The students further were required to earn at least $10 \%$ of the time card points from a programming category. Pair programming was allowed with each member of the pair splitting the points earned for completing a user story. The completed time cards were submitted to the team leader for approval and then forwarded to the instructor for grading.

In some cases, these activities were further refined. For example, level designers were awarded separate points for completing story board and level design templates in addition to hours spent editing a game level. Test engineers were rewarded for writing test cases, executing test cases, and documenting the test results. Programmers were not credited with work completed unless a user story satisfied its acceptance criteria. Some tasks such as asset creation or management tasks were better rewarded on an hourly basis. Typically, 1 point an hour was awarded for these tasks.

The gamification framework was implemented using the Gradecraft class management system [29]. This allowed the implementation of a leaderboard and provided access to a grade predictor tool. A badge system was also initiated to recognize outstanding achievement in many categories (leadership, game development, marketing, creative activities).

\section{EVALUATION}

The assessment of this course is ongoing. Students will be asked to complete the standard course evaluation form. Students will also be asked to answer online survey questions shown in Table II once the course is completed in April 2017. The student postmortems will also be examined for insights into what went well and what needs improvement.

Informal student comments made during the course suggest that the students are enjoying the move away from straight lecture in this class. They have embraced the use of the time cards as a way to document the individual efforts that go into making each game product. It is expected that a rich set of historic data will be available to help future groups of students estimate the effort required to complete game products of this size.

TABLE II. GAMIFIED LEARNING SURVEY

\begin{tabular}{|c|c|}
\hline \multirow[t]{2}{*}{$\begin{array}{l}\text { Mean } \\
\text { Score }\end{array}$} & $\begin{array}{l}\text { When picking assignments for this course what criteria } \\
\text { was important when deciding which assignment to } \\
\text { complete? }\end{array}$ \\
\hline & $1=$ not very important, $5=$ very important \\
\hline & How easy an assignment appeared to be \\
\hline & How long I thought it would take me to complete the assignment \\
\hline & How interested I was in doing the assignment \\
\hline & $\begin{array}{l}\text { Whether I had the necessary prior knowledge and skills to } \\
\text { complete the assignment }\end{array}$ \\
\hline & How many points I could earn by doing the assignment \\
\hline & $\begin{array}{l}\text { How much the assignment allowed me to collaborate with my } \\
\text { classmates }\end{array}$ \\
\hline & $\begin{array}{l}\text { Which of the following had an impact on your ability to } \\
\text { complete assignments in this class? }\end{array}$ \\
\hline & $1=$ not very little impact, $5=$ very big impact \\
\hline & The amount of time required to complete an assignment \\
\hline & The complexity of the assignments \\
\hline & $\begin{array}{l}\text { Your understanding of the assignment guidelines and } \\
\text { expectations }\end{array}$ \\
\hline & Your ability to manage your time successfully \\
\hline & $\begin{array}{c}\text { Please indicate your agreement with the following } \\
\text { statements. }\end{array}$ \\
\hline & 1=completely agree, 5 completely disagree \\
\hline & $\begin{array}{l}\text { I put more effort into the assignments for this class than I } \\
\text { normally do for the courses I take. }\end{array}$ \\
\hline & $\begin{array}{l}\text { I felt like I had more control and choice over the assignments I } \\
\text { completed for this class than I normally do. }\end{array}$ \\
\hline & $\begin{array}{l}\text { In this course, I did what I had to, but I didn't feel like it was } \\
\text { really my choice. }\end{array}$ \\
\hline & $\begin{array}{l}\text { In this course, I feel I had control over how I demonstrated my } \\
\text { understanding of the course material. }\end{array}$ \\
\hline
\end{tabular}

\section{CURRENT STATUS}

Assessment data is being collected for the Winter 2017 offering of CIS 488. The role-play scenarios are complete. The gamification framework and badge system have been implemented in Gradecraft. Student feedback will be used to improve both the role-play and gamification framework for the next offering of CIS 488 in Winter 2018.

\section{FUTURE WORK}

In addition to enhancing the scenarios, a more meaningful process for conducting both formative and summative assessment of CIS 488 is planned. The informal feedback on the gamification suggests that it might be adapted to other project based courses, with or without the role-play elements. In particular, the gamification framework will be modified for use in the Fall 2017 offering of CIS 487 Game Design and Implementation 1. 


\section{REFERENCES}

[1] Promoting

Active

Learning, https://utah.instructure.com/courses/148446/pages/active-learning, retrieved February 25, 2016.

[2] M. Prince. "Does Active Learning Work? A Review of the Research", Journal of Engineering Education, Vol. 93, 2004, pp. 223-231.

[3] P. K. Raju and C. S. Sanker. "Teaching Real-World Issues through Case Studies", Journal of Engineering Education. Vol. 88 No 4 pp501-508

[4] D. Simkins. The arts of larp: Design, literacy, learning, andcommunity in live-action role play. Jefferson, NC: McFarland, 2015.

[5] K. Moroz-Lapin. "Role play in HCI studies," in Proceedings of the 2009 international conference on HCI Educators: playing with our Education (HCIEd'09), British Computer Society, Swinton, UK, 2009, 12-12.

[6] G. Seland. "Empowering End Users in Design of MobileTechnology Using Role Play as a Method: Reflections on the Role-Play Conduction," in Proceedings of the 1st InternationalConference on Human Centered Design: Held as Part of HCI International 2009 (HCD 09), Masaaki Kurosu (Ed.). Springer-Verlag, Berlin, Heidelberg, 2009. 912-921.

[7] D. Zowghi \& S. Paryan, "Teaching Requirements Engineeringthrough Role Playing: Lessons Learnt," in Proceedings of the 11th IEEE International Conference on Requirements Engineering (RE '03). IEEE Computer Society, Washington, DC, USA, 2003, 233-241.

[8] J. Börstler. "Improving CRC-card role-play with role-play diagrams," in Companion to the 20th annual ACM SIGPLAN conference on Objectoriented programming, systems, languages, and applications (OOPSLA '05). ACM, New York, NY, USA, 2005, 356-364.

[9] T. Vold and S. Y. Yayilgan, "Playful participation for learningin higher education - The introduction of participatory role play simulation in a course at Hedmark University College," Information Technology Based Higher Education and Training(ITHET), 2013 International Conference on, Antalya, 2013, pp.1-4.

[10] A. Rudra, B. Jaeger, A. Aitken, V. Chang and B. Helgheim, "Virtual Team Role Play Using Second Life for Teaching Business Process Concepts," System Sciences (HICSS), 2011 44th Hawaii International Conference on, Kauai, HI, 2011, pp. 1-8.

[11] C.H. Brooks, "Community connections: lessons learned developing and maintaining a computer science service-learning program," in Proceedings of the 39th SIGCSE technical symposium on Computer science education (SIGCSE '08). Portland, OR, 2008, pp.352-356.

[12] J.A. Stone, E. Madigan, "Experiences with community-based projects for computing majors," J. Comput. Sci. Coll. vol.26, no.6, pp.64-70, June, 2011.

[13] T. Nakamura, H. Maruyama, A. Takashima and Y. Sambe, "Role-play exercises for project management education that incorporate a software agent," Teaching, Assessment and Learning for Engineering (TALE), 2012 IEEE International Conference on, Hong Kong, 2012, pp. W2A-8W2A-14.

[14] B.R. Maxim, R. Kaur, C. Apzynski, D. Edwards, and E. Evans. "An Agile Software Engineering Process Improvement Game", Proceedings of 46th IEEE Annual Frontiers in Education Conference, Erie, PA, October 2016, pp. S3F1-S3F5.

[15] E. Navarro and A. v. d. Hoek. "SimSE: An Interactive Simulation Game for Software Engineering Education', Proceeding of the Seventh IASTED International Conference on Computers and Advanced Technology in Education, pp. 12-17.

[16] A. Decker and D. Simkins "Leveraging Role Play tp Rxplore the Software and Game Development Process", Proceedings of 46th IEEE Annual Frontiers in Education Conference, Erie, PA, October 2016, pp. S3F6-S3F10.

[17] Deterding, S., Dixon, D., Khaled, R., \& Nacke, L. (2011). From Game Design Elements to Gamefulness: Defining "Gamification." Proceedings of the 2011 Annual Conference Extended Abstracts on Human Factors in Computing Systems - CHI EA '11, 2425.

[18] Domínguez Saenz-de-Navarrete, J., de-Marcos, L., Fernández-Sanz, L., Pagés, C., A., \& Martínez-Herráiz, J. J. (2013). Gamifying learning experiences: Practical implications and |routcomes. Computers \& Education, 380-392. $\quad$ Retrieved from https://portal.uah.es/portal/page/portal/epd2_profesores/prof23288/publi caciones/GamifLearningExperiences_pre-review_v3.1PreprintFinal.pdf

[19] Simões, J., Redondo, R. D., \& Vilas, A. F. (2012). A social gamification framework for a K-6 learning platform. Computers in Human Behavior, 29, 345-353. doi:10.1016/j.chb.2012.06.007

[20] Gee, J. P. (2014). What Video Games Have to Teach Us About Learning and Literacy. Second Edition. St. Martin's Press. Retrieved from https://books.google.com/books?id=v_XIBAAAQBAJ

[21] Gee, J. P. (2003). What Video Games Have to Teach Us About Learning and Literacy, 1(1), 1-4.

[22] Vygotsky, L. S. (1978). Mind and society: The development of higher mental processes.

[23] Granic, I., Lobel, A., E, C. M., \& Engels, R. C. M. E. (2014). The benefits of playing video games. American Psychologist, 69(1), 66-78.

[24] Ott, M., \& Tavella, M. (2009). A contribution to the understanding of what makes young students genuinely engaged in computer-based learning tasks. Procedia - Social and Behavioral Sciences, 1(1), 184188.

[25] Lee, J. J., \& Hammer, J. (2011). Gamification in education: what, how, Why Bother? Definitions and uses. Exchange Organizational Behavior Teaching Journal, 15(2), 1-5.

[26] Yang, Y. T. C. (2012). Building virtual cities, inspiring intelligent citizens: Digital games for developing students' problem solving and learning motivation. Computers and Education, 59(2), 365-377.

[27] D. Toth \& M. Kayler, "Integrating Role-Playing Games into Computer Science Courses as a Pedagogical Tool," in Proceedings of the 46th ACM Technical Symposium on Computer Science Education (SIGCSE '15). ACM, New York, NY, USA, 2015, 386-391.

[28] J. Schell. The Art of Game Design: A Book of Lenses. CRC Press, 2015.

[29] Gradeccraft Home Page, https://www.gradecraft.com/, retrieved April $11,2017$. 